\title{
Broad-Spectrum Human Papillomavirus Vaccine V505
}

National Cancer Institute

\section{Source}

National Cancer Institute. Broad-Spectrum Human Papillomavirus Vaccine V505. NCI

Thesaurus. Code C70598.

A non-infectious recombinant cancer vaccine prepared from the human papillomavirus (HPV) with potential immunoprophylactic activity. Vaccination with broad-spectrum human papillomavirus vaccine V505 may stimulate the host immune system to mount humoral and cytotoxic T lymphocyte $(C T L)$ responses against HPV-infected cells. HPV infection, the cause of genital warts, is a risk factor for the development of cancers of the cervix, vagina, vulva, anus, and penis. 